\title{
OPPORTUNITIES AND ISSUES IN INTERNATIONAL PHOTOVOLTAIC MARKET DEVELOPMENT
}

\author{
Roger Taylor, Doug Arent, Sam Baldwin, Robert McConnell, Jack Stone, Harin Ullal, Cecile Warner, William Wallace \\ National Renewable Energy Laboratory, 1617 Cole Blvd., Golden, CO 80401 \\ Paul Klimas, Elizabeth Richards, Charles Hanley, and John Strachan \\ Sandia National Laboratories, Albuquerque, NM 87185-0704
}

\begin{abstract}
The confluence of technology development and market readiness is opening up major business opportunities for photovoltaic (PV) systems throughout the developing world. The National Renewable Energy Laboratory (NREL) and Sandia National Laboratories in Albuquerque (Sandia), working on behalf of the U.S. Department of Energy, have launched pilot projects in several countries throughout the world over the past 3 years. The focus of these pilot projects has been the development of in-country institutional capabilities necessany to deliver the promise of PV electricity to the rural populations. In addition to country-specific activities, NREL is conducting several technology, information, and partnership projects focused on further accelerating the education, training, business, and technology developments necessary to bridge the gap between promise and reality. This paper summarizes these efforts.
\end{abstract}

\section{COUNTRY PROJECTS}

Country-specific, pilot-project partnerships have been developed and are being carried out in Brazil, India, China, South Africa, Mexico, and elsewhere. A common theme in all these country collaborations has been to team up with strong in-country affiliates to build on the existing in-country institutional capability.

\section{Brazil}

In Brazil, the Joint U.S./Brazilian Renewable Energy Rural Electrification Project was established following the Earth Summit in Rio de Janeiro in June 1992. In collaboration with the Centro de Pesquisas de Energia Eletrica (CEPEL) and the local state-owned electric utilities, installation of the hardware for Phase 1 of the project was completed in 1994 and nearly 800 PV lighting systems are continuing to operate successfully. Installation of Phase 2 hardware is now nearing completion in 5 additional states, where emphasis has expanded into other applications (water pumping by both PV and small wind-electric systems, stand-alone home electrification with basic ac power, two $50-\mathrm{kW}$ village-scale hybrid power systems for diesel-fuel displacement in the Amazon Basin, and additional home, school, and health clinic do power systems). The objectives of these pilot projects are to establish technical, institutional, and economic confidence in using renewable energy ( $\mathrm{PV}$ and wind) systems to meet the needs of the citizens of rural Brazil.

Of particular interest both in Brazil and elsewhere (particularly Indonesia) is the nearly economic opportunity for village-power retrofits. The northern region of Brazil, including most of the Amazon Rain Forest, is sparsely populated-10 million people living in 5 million $\mathrm{km}^{2}$, or less than $7 \%$ of the country's population in $56 \%$ of its total area. Electricity generation, where it exists, is mainly based on isolated thermal-electric systems ranging from a few kilowatts, in small villages, to tens of megawatts in the capital cities. There are more than 300 of these mini-grid systems operated by local utilities and thousands of privately owned systems. The cost of electricity from these systems is high and strongly dependent on system size. In the villages with diesel systems under $100 \mathrm{~kW}$, the cost can be more than US $\$ 0.50 / \mathrm{kWh}$. These high costs are due more to operation and maintenance costs and low capacity factor than to high fuel costs. The two hybrid power systems being installed in Joanes (Para) and Campinas (Amazonas) will demonstrate the technical opportunities (and problems) of operating PV-wind-batterydiesel hybrid power systems in remote locations in Brazil [1].

\section{India}

In India, activities are under way with the Ministry of NonConventional Energy Sources (MNES) and the West Bengal Renewable Energy Development Agency (WBREDA) to supply technical and economic support to the Ramakrishna Mission. The Mission is a well-respected humanitarian organization working in the general area of rural and subsistence-level dwellers. The Mission has identified the Sundarbans, the delta region of southern Bengal, where the Ganges River meets the Bay of Bengal, as an ideal area for the pilot project. The Mission will be responsible for educating and training the users of PV systems and for collecting the revenues from system owners.

Three hundred homes in seven villages will be provided with electric lights and auxiliary power sockets. In addition, a clinic, weaving facility, and youth club will receive lights and a vaccine refrigerator. Several battery-charging stations will be built, and a spice grinder and water pump will be PV powered. The villages will also receive street lights. Approximately $30 \mathrm{~kW}$ of PV panels (polycrystalline silicon) will be deployed.

This project is cost-shared 50-50 with the Ministry of Non-Conventional Energy Sources in India, who will provide batteries, compact fluorescent lamps, and other balance-ofsystem components. MNES will pay for custom duties and a 
technical consultants WBREDA and Exide Industries, Ltd. to assist in installation and maintenance. The Government of India will provide a $50 \%$ subsidy to purchase the home lighting systems and the system owners will be required to provide the remaining amount in the form of a down payment and future payment of a long term, low interest loan. By requiring direct user investment in the systems, a pride of ownership should provide a more serious interest in keeping the systems well maintained. In addition the owners will be required to pay a small amount into a maintenance fund which will be used to provide door-to-door service for maintaining the systems. The Ramakrishna Mission will use the down payment money to establish a revolving line of credit so that the systems can be replicated for other users in the area. It is expected that entrepreneurs will be attracted to invest in home lighting systems expansion and that the battery charging stations will represent an opportunity for a revenue producing venture. The Mission will provide the banking and revenue collection functions in the area. By involving the women of the village in the use of the systems, their empowerment in being actively involved in caring for the systems will be a positive force in the villages.

Based on the success of this project, the Mission will raise additional funds to purchase and promote cost-effective system installations.

\section{China}

Rapid growth in economic development coupled with the absence of an electric grid in large areas of the rural countryside have created a need for new energy sources both in urban centers and rural areas in China. The Ministry of Electric Power in China has announced that China needs to install 100 to $130 \mathrm{GW}$ of new electric generating capacity by the year 2000 to meet the demands of the growing economy. Concerns over environmental pollution from the increased use of coal-fired steam turbines to meet this capacity expansion is a growing concern. As a consequence of these factors, there is a growing interest in China for the development of renewable energy resources and technologies to meet energy demands and help mitigate pollution problems. Interest in the use of renewable energy is reflected both at the central government level in Beijing and at the local level in the provinces and autonomous regions of China.

China has an abundance of renewable energy resources in the form of solar, wind; biomass, hydro, geothermal, and ocean tidal resources. China is also already one of the world's largest users of renewables, primarily in the form of hydropower and biomass. The solar resource of the country is also enormous and is strategically located in areas of the greatest need in terms of rural energy development. There are more than 120 million rural people in northern and western China and over 300 coastal islands that currently have no access to the electric power grid and no near-term prospects for grid connection. There is an excellent match of solar and also wind resources to meet the rural electrification needs of these people.

The current installed capacity of PV systems in China is small, but growing rapidly. In 1993, the installed capacity of PV systems was about $3.5 \mathrm{MW}_{\mathrm{p}}$, and by 1995 the installed capacity was about $5 \mathrm{MW}_{\mathrm{p}}$. Most of this capacity $(60 \%)$ is power for telecommunications applications. About $1.5 \mathrm{MW}_{\mathrm{p}}$ is installed in remote, agricultural, and village power applications, for which opportunities exist throughout China. There are more than 10,000 rural household systems already installed, mostly in Inner Mongolia, Tibet, and Qinghai. Household systems are generally in the range of 20 to $80 \mathrm{~W}$ and are used for lighting and small consumer electronics. The largest PV systems are in the range of 10 to $25 \mathrm{~kW}$, most of which are village demonstration systems in Tibet. There is experience with wind/PV hybrid systems in the range of 200 $W$ to $35 \mathrm{~kW}$. There is at present no experience with gridconnected PV systems in China. However, the quality of grid power is a pervasive problem, and the use of PV for gridsupport, uninterruptible power supplies, and peak-shaving applications in the potential urban market is of high interest in China.

in the central government of the People's Republic of China, there are three commissions under the State Council that are actively involved in renewable energy: the State Planning Commission (SPC), the State Economic and Trade Commission (SETC), and the State Science and Technology Commission (SSTC). The SPC is in charge of planning and budget approval for large infrastructure projects. The SETC is in charge of industrialization and retrofitting existing industries. The SSTC is in charge of planning and program administration of scientific research and development projects. Project implementation and management are the responsibilities of various ministries, such as the Ministry of Electric Power (MEP) and the Ministry of Agriculture (MOA). In February, 1995, Hazel O'Leary, Secretary of the U.S. Department of Energy (DOE), signed the Energy Efficiency and Renewable Energy protocol agreement with the State Science and Technology Commission in Beijing that established a broad umbrella for Sino/American cooperation to develop renewable energy technologies and markets in China.

Prior to and since the signing of the protocol agreement, DOE has been working closely with key departments in the SPC, SSTC, and SETC to provide assistance and support for China's renewable energy planning activities. Such activities include preparation of the Agenda 21, "White Paper on China's Population, Environment, and Development in the 21 st Century," and encouragement for renewable energy project development for China's Ninth Five-Year Plan, for the period of 1996 to 2000. Under the framework for cooperation established by the protocol agreement, DOE is pursuing development of three project annexes: (1) with the Chinese Ministry of Agriculture for rural energy development; (2) with key organizations for wind energy and hybrid system cooperation, and (3) for business development activities in cooperation with the SETC. NREL is providing assistance to DOE for implementing projects under the protocol agreement in China.

The high cost, lack of a marketing and distribution infrastructure, and variable quality of modules and balance-ofsystem components are barriers to the widespread deployment of photovoltaics in China. Several cooperative projects are being conducted in China to address these problems. Under the protocol agreement, NREL is working with the MOA and the Chinese State Council Office of Poverty Alleviation and Rural Development to develop a cost-shared program to provide household PV electricity systems to rural families in Western China. This project is being conducted with the Solar Electric Light Fund (SELF) in Washington, D.C., and is designed to expand and strengthen the 
distribution infrastructure previously established in Gansu province in China. This infrastructure involves a partnership between the rural energy offices at the county level (under the MOA), provincial government agencies associated with poverty alleviation, and local PV system integrators in China. Rural energy offices exist at the district and county level in almost every province in China and can help facilitate rural electrification projects throughout China, providing a widespread infrastructure for technology deployment. The use of revolving credit funds for financing the purchase of household systems to expand the market for PV is a critical component of the project.

In collaboration with the Chinese Academy of Science in Beijing and the Center for Energy and Environmental Policy at the University of Delaware in the United States, NREL is also working with several agencies of the Inner Mongolian government and several key investors in Inner Mongolia to develop PV and PV/wind hybrid projects in Inner Mongolia. A series of case studies is being conducted for household and village-power systems to develop technical and economic performance data and information. The government of Inner Mongolia is committed to a village electrification program over the next 5 years, which will involve a number of villages that will be electrified using renewable energy technologies. Inner Mongolia also has an established distribution infrastructure for rural energy-system deployment at the county and village level that can provide an infrastructure for PV market development. Involvement of the local electricity bureau is a key component of this project. Local electricity bureaus at the provincial and county level potentially represent a national infrastructure for technology deployment throughout China [2].

\section{South Africa}

Dramatic political changes in South Africa have prompted an unprecedented effort to improve social equity of the majority of South Africans. A vital component of this effort addresses the energy requirements of the poor. This includes providing power for basic lighting and for productive uses to some 20 million citizens who do not currently have access to the existing transmission and distribution system. Aggressive programs are currently under development in South Africa for the electrification of rural clinics, schools, and homes. Although basic lighting for improved quality of life, health, and education are critical near-term efforts, long-term sustainable development requires improved economic development. Renewable energy resources offer tremendous benefits to the energy, economic, and social challenges South Africa faces.

The South African photovoltaic market is multidimensional, with an existing commercial sector that serves the game reserves, national parks, telecommunications network, and farmers. Additionally, and with the new government, three programs have been developed for rural electrification: schools, medical clinics, and domestic systems.

The schools program has been funded initially by the Government of National Unity (GNU) and is administered by Eskom, the national parastatal electricity utility. The program hopes to electrify 16,000 schools over 5 years at about $500 \mathrm{~W}$ each, with associated building wiring and audio-video equipment.

The medical clinics program is run by the Independent Development Trust (IDT) and has a target of about 2000 clinics. This program is fully functional and electrifies about 10 clinics per month through an extensive network of field agents, many of whom also work with other development portfolios such as agriculture and small business development. A typical clinic system is rated at $900 \mathrm{~W}$, and about 200 installations have already been completed.

The domestic households program began in 1995 and is formulated under a new company called Renewable Energy for South Africa (REFSA), which is a subsidiary of the Central Energy Fund, and under the oversight of the Department of Mineral and Energy Affairs. The DOE brokered US AID (U.S Agency for International Development) funding of $\$ 1.1$ million as a cost-share of the pilot phase, now administered by ECRE/REFAD (the U.S. Export Council for Renewable Energy/Renewable Energy for African Development). DOE has also been instrumental in developing implementation ideas and bringing international financing institutions into the discussions. REFSA has received technical assistance from NRECA (the National Rural Electric Cooperative Association), Sandia, and NREL.

DOE has a broad and coordinated effort looking at the complete energy sector in South Africa. The Department's efforts also include strong efficiency components, capacity building programs, technical exchange, and policy development. For renewable energy, the DOE has worked in partnership with both NREL and Sandia National Laboratories on a multi-tiered program that includes building manufacturing capability, market development, technical interchange for $R \& D$, and pilot testing of a variety of technologies.

Cooperation between Spire Corporation and in-country partners Renaissance (a South African empowerment and investment company), AEG (Pty) Limited (affiliated with ASE Americas), the University of Port Elizabeth, and others has led to the establishment of Suncorp, a black-owned business for PV module assembly and solar system supply to a wide variety of emerging PV markets in South Africa. Suncorp will provide locally manufactured product that will help meet the needs of the South African Reconstruction and Development Programme's efforts to stimulate the socio-economic development of disadvantaged communities in South Africa. A key to successful expansion of rural electrification is the development of a local marketing, distribution, maintenance, and financing infrastructure. Independent of the Suncorp efforts, NREL and Sandia are also working with local incountry affiliates to pilot a Solar Enterprise Initiative that will establish local franchises with commercial financing as part of the REFSA program.

\section{Mexico}

Mexico represents a major potential market for photovoltaics. Mexico has more than 80,000 villages, representing 7 million people with no access to grid-supplied electricity or its associated economic opportunities; a potential market on the order of $\$ 1$ billion. Over 100,000 communities are without potable water, another $\$ 1$ billion potential market. The agricultural sector offers even larger opportunities; as examples, there are 600,000 cattle ranches in need of water pumping, representing a $\$ 6$ billion potential market, as well as a great need for irrigation systems for citrus and other crops. The Mexican government has recently shown considerable interest in renewables, subsidizing the purchase of more than 30,000 solar home-lighting systems over the last few years and incorporating renewables components into some of its 
federal agencies. However, aside from the solar home systems, the other market sectors remain largely untapped, and Mexico is implementing a variety of development programs, particularly in the agricultural sector, that offer excellent opportunities for PV if the agencies involved can acquire the capabilities necessary for accessing and using the technology. The North American Free Trade Agreement and Mexico's proximity to the United States offer special advantages to the U.S. industry.

Sandia and NREL are implementing a multi-year program in Mexico to facilitate the use of renewable energy, primarily $P V$ and wind, in rural, off-grid, productive-use applications. This program is co-sponsored by the DOE and the USAID. Like other programs described in this paper, the approach by Sandia and NREL emphasizes sustainability and the development of in-country institutional capacity. The program team is working with established Mexican organizations and within established and funded programs to incorporate the use of renewable energy technologies where they are the best technical and economic solution. The team provides training and technical assistance and uses the implementation of pilot projects as a tool to institutionalize the use of renewableenergy technologies. About 30 cost-shared PV systems have been installed to date, and more than 100 systems will be installed by the end of 1996. Also, significant near-term replication of these projects is under way, as the Fideicomiso de Riesgo Compartido (FIRCO - a federal shared-risk trust fund under Mexico's agriculture department) initiates a major $\$ 225$ million development program. Sandia and NREL are providing technical assistance as FIRCO begins to implement hundreds of PV and wind projects, with equipment purchases made entirely with Mexican funds (no U.S. cost share).

Productive-use applications are those that provide an economic or social benefit to the end-user. They have a high degree of sustainability and replicability because a means for paying for the systems is builtin. Examples include water pumping for livestock or crop irrigation, lighting for commercial or business activities, communications, power for graingrinding or carpentry, and ecotourism.

The Sandia/NREL Mexico program is divided into specific projects and cross-cutting activities. The projects include working with FIRCO at both the state and national levels, along with state-agency activities in several states, including Chihuahua, Sonora, Baja California Sur, and Quintana Roo. In addition, the program has cooperative projects under way with Conservation International, The Nature Conservancy, World Wildlife Fund, and their local Mexican partner organizations to incorporate the use of renewable energy into ongoing protected-areas management activities in Mexico. Cross-cutting activities include solar and wind resource assessment, training, technical and economic analysis, financing mechanisms, industry interactions, project monitoring and evaluation, and environmental assessments.

\section{DEVELOPMENT STRATEGY}

A common theme in all these country collaborations has been to team up with strong in-country affiliates to build on the existing in-country institutional capability. Different types of organizations have emerged in each country. In Brazil, the electric utility industry is a key player. In China, the rural energy offices of the Chinese Ministry of Agriculture are key players. In India, the non-governmental Ramakrishna Mission is a key player. In South Africa, diverse governmental and private-sector capabilities are being focused on developing new institutions. And in Mexico, federal and state agricultural development agencies have emerged as strong partners. The key issue in PV commercialization is the development of these institutional capabilities as rapidly as possible.

Toward that end, our efforts are increasingly focused on developing in-country institutional capability. Activities include the following:

- Internships to train in-country professionals

- System design software for renewable energy and hybridsystem analysis

- Educational and media communication tools to train local experts in effectively relaying the renewables message

- Policy consultation to facilitate informed decision-making by local officials

- Academic programs to further educate engineers and scientists, in cooperation with U.S. colleges and universities

- Financial support through linkages with international financing institutions

- Development of local in-country centers of excellence to facilitate technology transfer and project expertise

- Electronic information access to provide rapid, up-to-date information on products, literature, projects, design tools, financing, and contacts

- Specialized technology consultation for country-specific needs

- Testing and evaluation services to ensure reliable systems and components under local conditions.

International partnerships are helping to accelerate both the development and the implementation of renewable energy technologies. Although these efforts span across the entire range of renewable technologies, $\mathrm{PV}$ is often the entry point. Moving into the next century, it is increasingly important to work more closely with government agencies, utilities, businesses, research laboratories, development and investment organizations, and consumer and community groups to support sustainable economic development through the worldwide use of renewable-energy technologies.

\section{REFERENCES}

[1] C. Warner, R. Taylor, M. Moszkowicz, and C. Ribeiro, "PVHybrid Village Power Systems in Amazonia," Twenty-fifth IEEE PVSC, 1996

[2] W. Wallace and S. Tsuo, "Sino/American Cooperation for PV Development in the People's Republic of China," Twentyfifth IEEE PVSC, 1996.

[3] J. L. Stone and H. S. Ullal, "PV Opportunities in India," 13th NREL Photovoltaics Program Review, AIP Conference Proceedings 353, 1995 